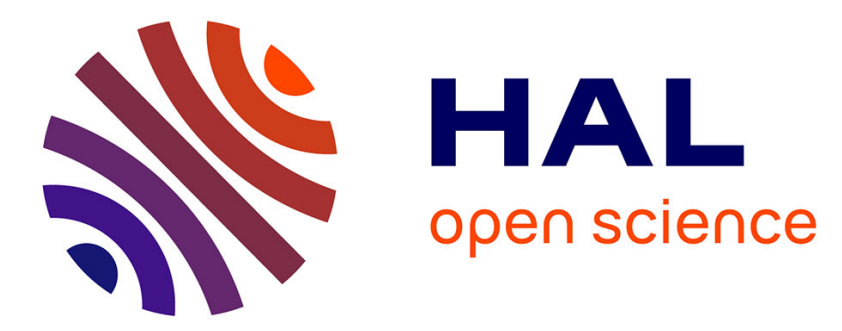

\title{
Diversity and prevalence of gastrointestinal parasites in two wild Galago species in Gabon
}

\author{
Larson Boundenga, Cyr Moussadji, Illich Manfred Mombo, Barthélémy \\ Ngoubangoye, Jean Bernard Lekana-Douki, Jean-Pierre Hugot
}

\section{- To cite this version:}

Larson Boundenga, Cyr Moussadji, Illich Manfred Mombo, Barthélémy Ngoubangoye, Jean Bernard Lekana-Douki, et al.. Diversity and prevalence of gastrointestinal parasites in two wild Galago species in Gabon. Infection, Genetics and Evolution, 2018, 63, pp.249-256. 10.1016/j.meegid.2018.04.035 . hal-01826453

\section{HAL Id: hal-01826453 \\ https://hal.sorbonne-universite.fr/hal-01826453}

Submitted on 29 Jun 2018

HAL is a multi-disciplinary open access archive for the deposit and dissemination of scientific research documents, whether they are published or not. The documents may come from teaching and research institutions in France or abroad, or from public or private research centers.
L'archive ouverte pluridisciplinaire HAL, est destinée au dépôt et à la diffusion de documents scientifiques de niveau recherche, publiés ou non, émanant des établissements d'enseignement et de recherche français ou étrangers, des laboratoires publics ou privés. 
Research paper

\title{
Diversity and prevalence of gastrointestinal parasites in two wild Galago species in Gabon
}

\author{
Larson Boundenga ${ }^{\mathrm{a}, \mathrm{b}, *}$, Cyr Moussadji ${ }^{\mathrm{b}}$, Illich Manfred Mombo ${ }^{\mathrm{c}}$, Barthélémy Ngoubangoye ${ }^{\mathrm{b}}$, \\ Jean Bernard Lekana-Douki ${ }^{\mathrm{a}, \mathrm{d}}$, Jean-Pierre Hugot ${ }^{\mathrm{e}, * *}$ \\ a Groupe Évolution et Transmission Inter-espèces de Parasites (GETIP), Unité Évolution, Épidémiologie et Résistances Parasitaires, CIRMF, BP769 Franceville, Gabon \\ ${ }^{\mathrm{b}}$ Centre de Primatologie (CDP), CIRMF, BP769 Franceville, Gabon \\ ${ }^{\mathrm{c}}$ Département de zoonoses et maladies émergentes, CIRMF, BP769 Franceville, Gabon \\ d Département de Parasitologie-Mycologie Médecine Tropicale, Faculté de Médecine, Université des Sciences de la Santé, B.P. 4009 Libreville, Gabon

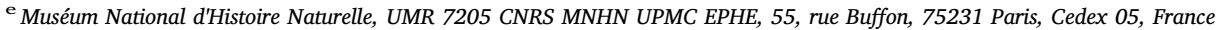

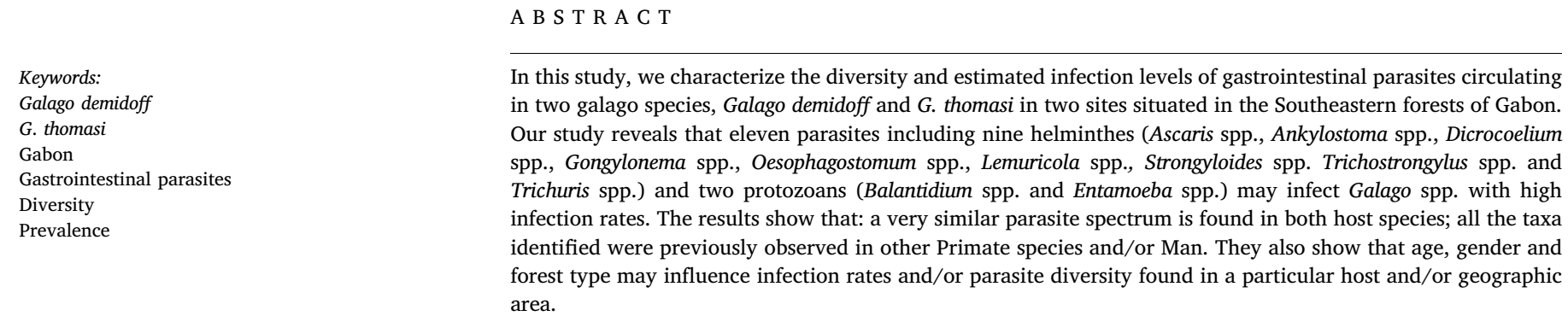

\section{Introduction}

Pathogens are playing a central role in ecosystems and community biodiversity due to their impact on the dynamic of populations growth and regulation (Hochachka and Dhondt, 2000; Hudson et al., 2002). A review of the literature shows that about $90 \%$ of the parasites recorded in Man include another mammal species in their cycle (Ashford and Crewe, 2003; Hugot et al., 2001). If animal's infectious diseases and parasitosis are a major threat for the conservation of wild species they also are a potential threat for human health (Lyles and Dobson, 1993) and the increasing conquest of the rain forest environments by men heighten the probability of parasite host switching. Phylogenetic proximities between Man and other hosts like NHPs (non-human primate species) are an important factor in pathogens exchanges (Wolfe et al., 2007). Consequently, it is important to determine the diversity of pathogens circulating in wildlife, and particularly among species endangered because of human activities (Daszak et al., 2000). In this context, the data on patterns of parasitic infections in wild primate populations may provide an estimation of population health and allow to assess and manage disease risks (Gillespie, 2006).
Gabon is a central African country whose forests covers 85 of the area and are among the richest in Africa in terms of animal diversity. The estimated fauna comprises $>190$ mammal species, including at least 20 species of monkeys, $>600$ bird species, 86 reptile species and 100 species of amphibians (Alonso et al., 2006; Pauwels et al., 2006). Several species of nocturnal NHPs are living in Gabon including: Galago demidoff G. Fischer, 1806 and G. thomasi Elliot, 1907 (Wilson and Reeder, 2005). Galagos (bushbabies) are threatened by an increasing fragmentation of their habitat due to human activities, but last studies on these species were done long time ago and very few data are available about their parasites. In the following, using faecal samples collected in these hosts in Gabon, we examined the diversity and prevalence of gastrointestinal parasites from these two closely related species, in different study sites.

\section{Materials and methods}

\subsection{Ethics statement}

The study was conducted in Gabon. All samples were collected in

\footnotetext{
* Corresponding author at: Groupe Évolution et Transmission Inter-espèces de Parasites (GETIP), Unité Évolution, Épidémiologie et Résistances Parasitaires, CIRMF, BP769 Franceville, Gabon.

*** Corresponding author.

E-mail addresses: boundenga@gmail.com (L. Boundenga), hugot@mnhn.fr (J.-P. Hugot).
} 


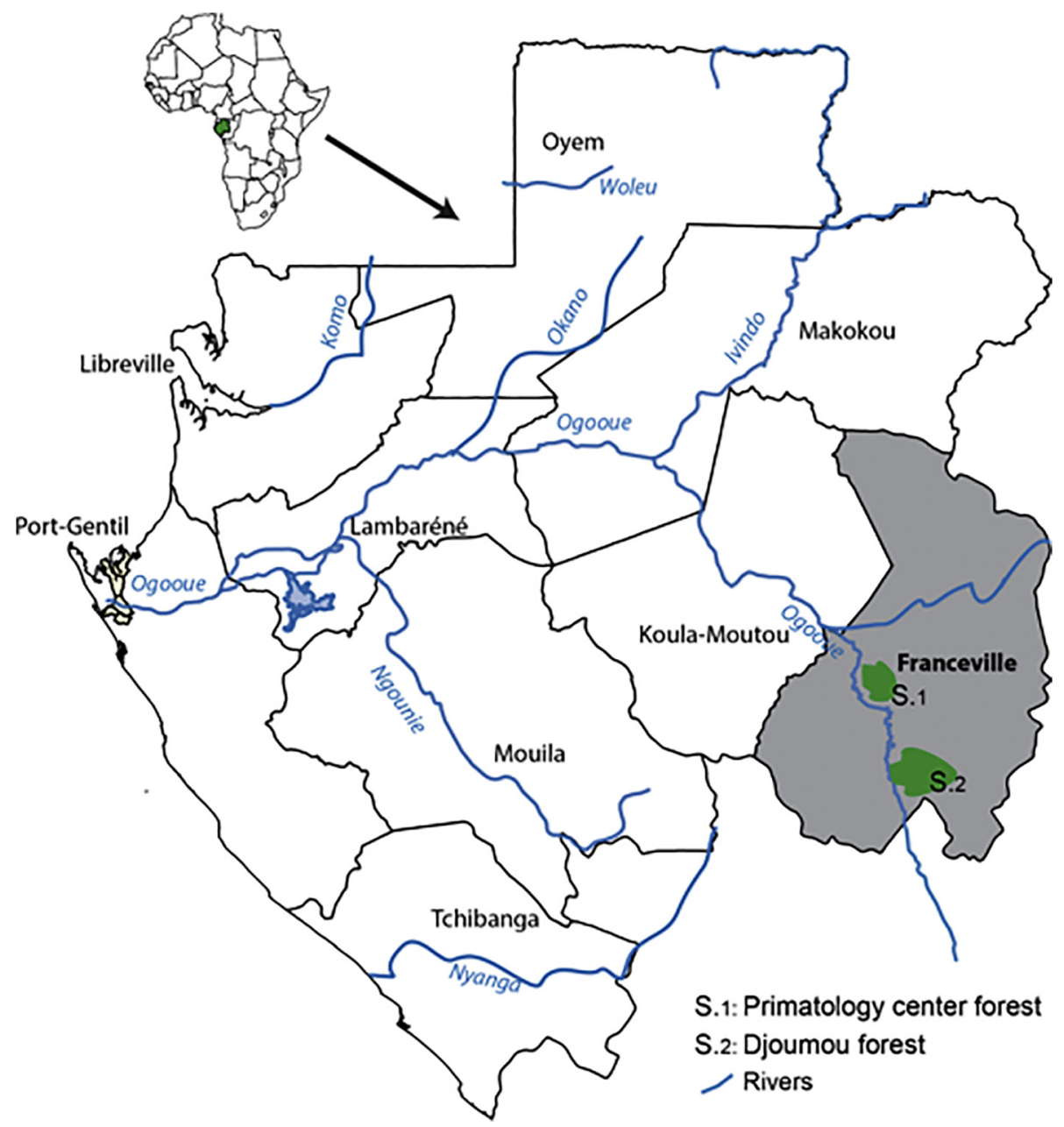

Fig. 1. Map of the study sites in South-east Gabon. Distance between S.1 Primatology Center forest (CDP) and S.2 Djoumou forest (DJM): approximately 30-40 km.

areas excluding national parks and protected areas and with the authorization of the Gabonese Ministries of Water and Forestry, Higher Education, Scientific Research and Innovation (N AR0031/09/MENESRESI/CENAREST/CG/CST/CSAR). During faecal collections, animal welfare was taken into consideration and each animal was released into its environment after the collect of biological material.

\subsection{Sites for collection of NHPs}

Research of gastro-intestinal parasites was conducted from February 2016 to January 2017 (11 months) on two different host species and two sites located in the province of Haut-Ogooué, Southeast Gabon (Fig. 1): the forest of the Primate Centre (CDP) of the "Centre International de Recherches Médicales de Franceville" (CIRMF) and the "Djoumou forest" (DJM) located between 30 and $40 \mathrm{~km}$ from Franceville. In CDP, forest habitats are divided into various relictual areas submitted to disturbances resulting from human activities. DJM forest covers a wider area than CDP and human presence is limited to traditional plantations and hunter's paths. Galagos were collected using Tomahawk traps (Duplantier, 1989; Malcolm, 1991) placed in trees for six consecutive nights at different heights. All animals collected were kept in black room (without light) until faecal samples may be collected. Galagos species identification was performed using Kingdon (1997) and Wilson and Reeder (2005). Parameters such as host species, sex, age appraisal and sampling season were documented during the collections.

\subsection{Faecal samples collection and examination}

A total of 147 bushbabies: G. demidoff $(n=83)$ and G. thomasi $(n=64)$ were examined. Faecal samples were analyzed via sodium nitrate flotation and faecal sedimentation following the protocol of Gillespie (2006). Detection and counting of parasite eggs, larvae, and cysts was performed using a compound microscope (objective $\times 10$ ). We used the $\times 40$ and $\times 100$ objectives to take pictures (Fig. 2). Identification of parasites is based on eggs shell and nucleus morphology according to Chitwood et al. (1950), Golvan (1990), Ashford and Crewe (2003). Together with Combes (1995) and Anderson (2000), the same books were used to obtain information about the parasites biology and their host spectrum.

\subsection{Statistical analyses}

Statistical analyses performed using $\mathrm{R}$ software. Infestation rates between species, sexes and age groups calculated and compared using the Chi-square $\left(\chi^{2}\right)$ method. Differences were considered statistically significant at 0.05 confidence level.

\section{Results}

Here after we consider successively the different parasite taxa in relation to the importance and variations of their prevalence in different hosts (Fig. 2 and Tables). We also try to relate these variations to what we know about the cycle, host specificity and taxonomic status of the parasites. The identification of the parasites collected during our 

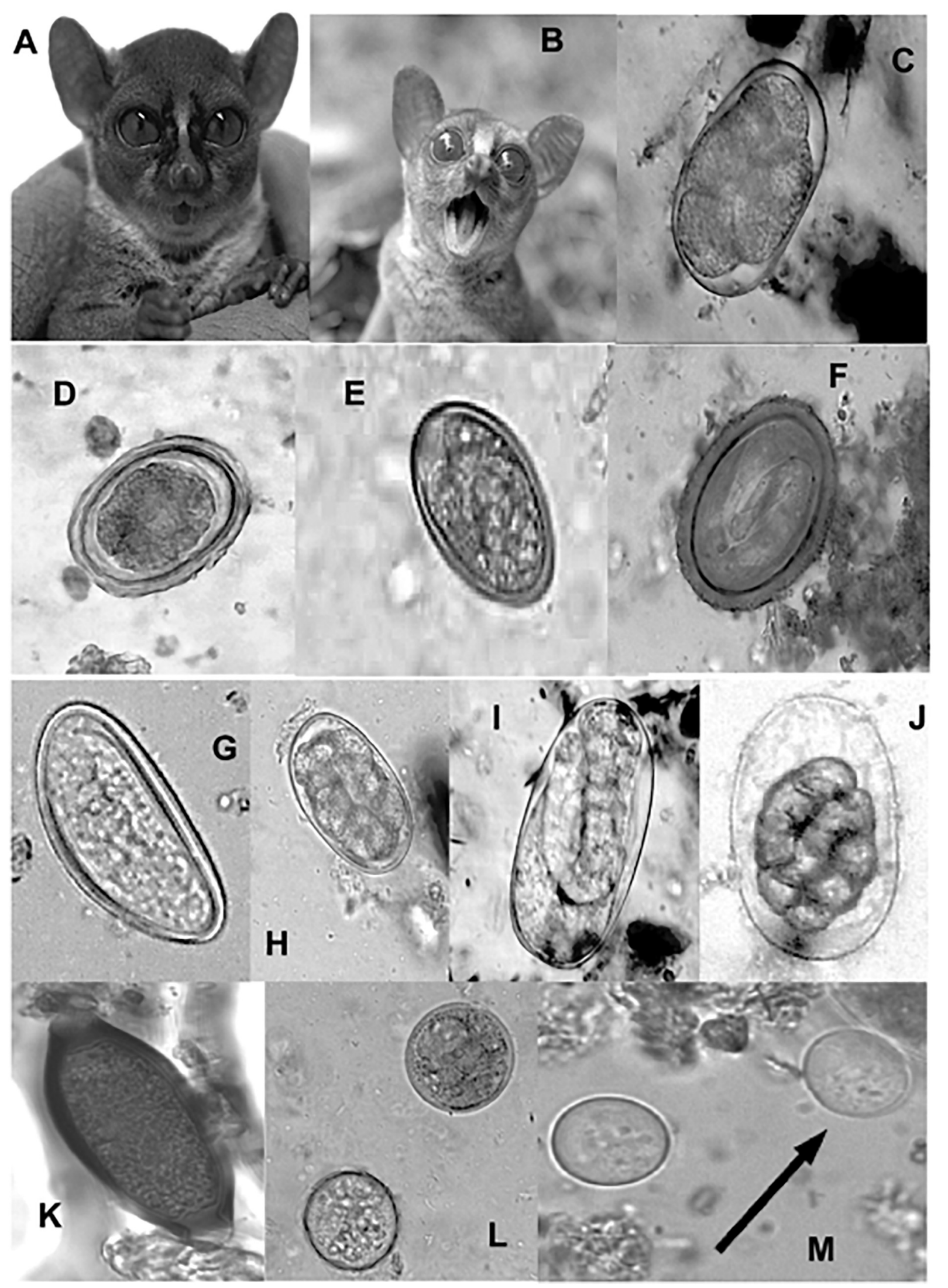

Fig. 2. Species included in the study. Host: A, Galago demidoff; B, Galago thomasi. Helminthes: C, Ancylostoma spp.; D, Ascaris spp.; E, Dicrocoelium spp.; F, Gongylonema spp.; G, Lemuricola spp.; H, Oesophagostomum spp.; I, Strongyloides spp.; J, Trichostrongylus spp.; K, Trichuris spp. Protozoa: L, Balantidium spp.; M, Entamoeba spp. 
Table 1

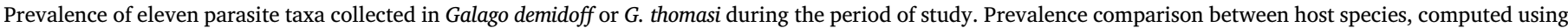

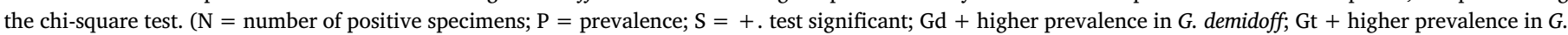
thomasi).

\begin{tabular}{|c|c|c|c|c|c|c|c|c|c|c|c|}
\hline \multirow[t]{2}{*}{ Parasites species } & \multicolumn{2}{|c|}{ Galagoides demidoff } & \multirow[t]{2}{*}{ Hosts } & \multicolumn{2}{|c|}{ Galagoides thomasi } & \multirow[t]{2}{*}{$X 2$} & \multirow[t]{2}{*}{$d f$} & \multirow{2}{*}{$\begin{array}{l}\text { Comparison test } \\
\text { p-Value }\end{array}$} & \multirow[t]{2}{*}{ S } & \multirow[t]{2}{*}{$\mathrm{Gd}+$} & \multirow[t]{2}{*}{$\mathrm{Gt}+$} \\
\hline & $\mathrm{N} / 83$ & $\mathrm{P}(\%)$ & & $\mathrm{N} / 64$ & $\mathrm{P}(\%)$ & & & & & & \\
\hline \multicolumn{12}{|l|}{ Helminths } \\
\hline Strongyloides spp. & 52 & 62.7 & & 7 & 10.9 & 16.83 & 1 & 4.09E-05 & + & + & \\
\hline Ancylostoma spp. & 8 & 9.6 & & 5 & 7.8 & 0.97 & 1 & 0.324 & - & + & \\
\hline Gongylonema spp. & 5 & 6.0 & & 3 & 4.7 & 0.00 & 1 & 1 & - & + & \\
\hline Lemuricola spp. & 3 & 3.6 & & 0 & 0.0 & 0.85 & 1 & 0.36 & - & + & \\
\hline Ascaris spp. & 26 & 31.3 & & 26 & 40.6 & 0.41 & 1 & 0.52 & - & & + \\
\hline Oesophagostomum spp. & 8 & 9.6 & & 25 & 39.1 & 9.94 & 1 & $1.62 \mathrm{E}-03$ & + & & + \\
\hline Trichostrongylus spp. & 1 & 1.2 & & 15 & 23.4 & 0.89 & 1 & 0.34 & - & & + \\
\hline Dicrocoelium spp. & 6 & 7.2 & & 6 & 9.4 & 0.02 & 1 & 0.896 & - & & + \\
\hline Trichuris spp. & 3 & 3.6 & & 6 & 9.4 & 0.00 & 1 & 1 & - & & + \\
\hline \multicolumn{12}{|l|}{ Protozoa } \\
\hline Balantidium spp. & 16 & 19.3 & & 10 & 15.6 & 0.07 & 1 & 0.789 & - & + & \\
\hline \multirow[t]{2}{*}{ Entamoeba spp. } & 6 & 7.2 & & 6 & 9.4 & 0.90 & 1 & 0.344 & - & & + \\
\hline & & & & & & & & & & 5 & 6 \\
\hline Mean & 12.2 & 14.7 & & 9.9 & 15.5 & & & & & & \\
\hline Median & 6 & 7.2 & & 6 & 9.4 & & & & & & \\
\hline
\end{tabular}

study is based on the light microscope observation of the eggs or cysts found in the faecal samples and by comparison with similar documents found in the literature. This method doesn't allow a precise determination of the parasite at the species level and in the following we identify the positive samples at the generic level only. The genus name used is that of the parasite of the same type (order, suborder, family) also found in other Primates, including Man. When several names were available we chose the most probable of them in relation to the particularities of the parasite cycle and the systematic position of the hosts. For most of the parasites, we also had to consider the possibility that each of the taxonomic units distinguished in this study may include different parasite species; for instance following which locality and/or host species is considered. This is the reason why we are systematically using here after the abbreviation "spp".

\subsection{Ancylostoma spp.}

The prevalence values are comprised between 7.5 and 10 and are twice as high in CDP than in DJM for both host species (Table 1). The prevalence is higher in females than in males (5.1 vs 13.2) and more than ten times higher in the young than in the adults (22.2 vs 2.1) (Table 3). After Anderson (2000) infection with hookworms is due to the penetration of larvae (L3) through the skin or by direct ingestion of dirt or fresh vegetables containing filariform larvae. They are parasite of the small intestine of mammals. Such parasites where identified as Necator spp. in both gorillas and chimpanzees by Graber and Gevrey (1981) in Congo. Kouassi et al. (2015) also signal hookworms, identified as Necator sp. or Ancylostoma sp., in several different guenon species in the Tai forest (Ivory Coast) sometimes with a high prevalence value ( $>$ 70). Because Malekani et al. (2014) signal Ancylostoma spp. in G. demidoff and G. gabonensis in the Democratic Republic of Congo with a high prevalence: 25.3 and 50 respectively; also because Golvan (1990) remarks that Ancylostoma eggs contain 4 blastomers only when laid, whereas Necator eggs contain 8, the parasites observed in our work must more likely be identified as Ancylostoma spp.

\subsection{Ascaris spp.}

This parasite exhibits one of the highest prevalence values observed in our study: 63.2 in G. thomasi and in CDP. For both host species the prevalence is higher in CDP than in DJM (Table 2) and in the males than in the females (Table 3). The Ascaridoidea are parasitic for vertebrate hosts: contamination results from ingesting food (vegetables or fruits) soiled in contact with earth or by drinking water. Genus Ascaris spp. are the single taxa in this group recorded in Primate hosts and, within the NHPs, they were observed in apes (gorillas and chimpanzees) (Graber and Gevrey, 1981) and in G. demidoff by Malekani et al. (2014) with a prevalence of 37.04. In both publications the authors identify the parasites collected in Primates as A. lumbricoides, the parasite of Man. However this identification looks dubious because $A$. lumbricoides is generally described as highly specific and unable to maintain itself in another host than man (Anderson, 2000; Ashford and Crewe, 2003).

\subsection{Balantidium spp.}

For both host species the prevalence for this parasite is not very different (19.3 vs 15.6) (Table 1). The prevalence is markedly highest in CDP than DJM, relatively close between males and females (15.2 vs 20.6), and very different between adults or young (24.7 vs 4.0) (Tables 2 and 3). Balantidium coli is a cosmopolitan parasite of the large intestine of the pig, but it is also found in vicarious hosts: Primates (macaques, guenons), Rodents (especially rats), dogs, cats and cattle. The cysts resist $>3$ months in the wild and can be carried by flies (Golvan, 1990). This parasite has been identified in several species of African guenons (Kouassi et al., 2015) living in the rain forest, in which it appears to be relatively frequent and abundant. These characteristics, the indisputable ubiquity of this parasite and its proven presence in the same habitats make its presence in the galagos very likely.

\subsection{Dicrocoelium spp.}

For both host species the prevalence values are similar and relatively weak $(<10)$ (Table 1$)$; the contrast between the two sites is marked: prevalence is two to eight times higher in CDP (Table 2); the males are twice as parasitized as the females; the prevalence values are identical in adults or young: around 8 (Table 3). Dicrocoelium spp. live mainly in the bile ducts and gall bladders of domestic and wild ruminants but occasionally parasitize primates including Man. They use insects, especially ants, as intermediate hosts (Kouassi et al., 2015). Ingesting infected ants or food contaminated by ants infects monkeys. This way of contamination is accessible to galagos, which are insectivorous. Golvan (1990) describes the true parasitism by Dicrocoelium as exceptional in Man, but signals the frequent finding of eggs in transit, in the feces. This remark may very probably be extended to other primates and is corresponding with our present observation. 
Table 2

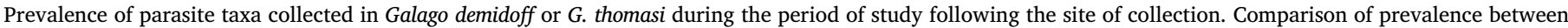

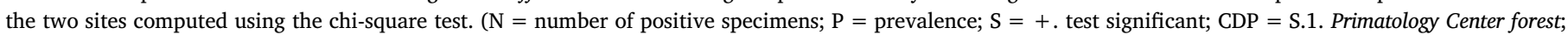
DJM = S.2. Djoumou forest; + higher prevalence in CDP or DJM).

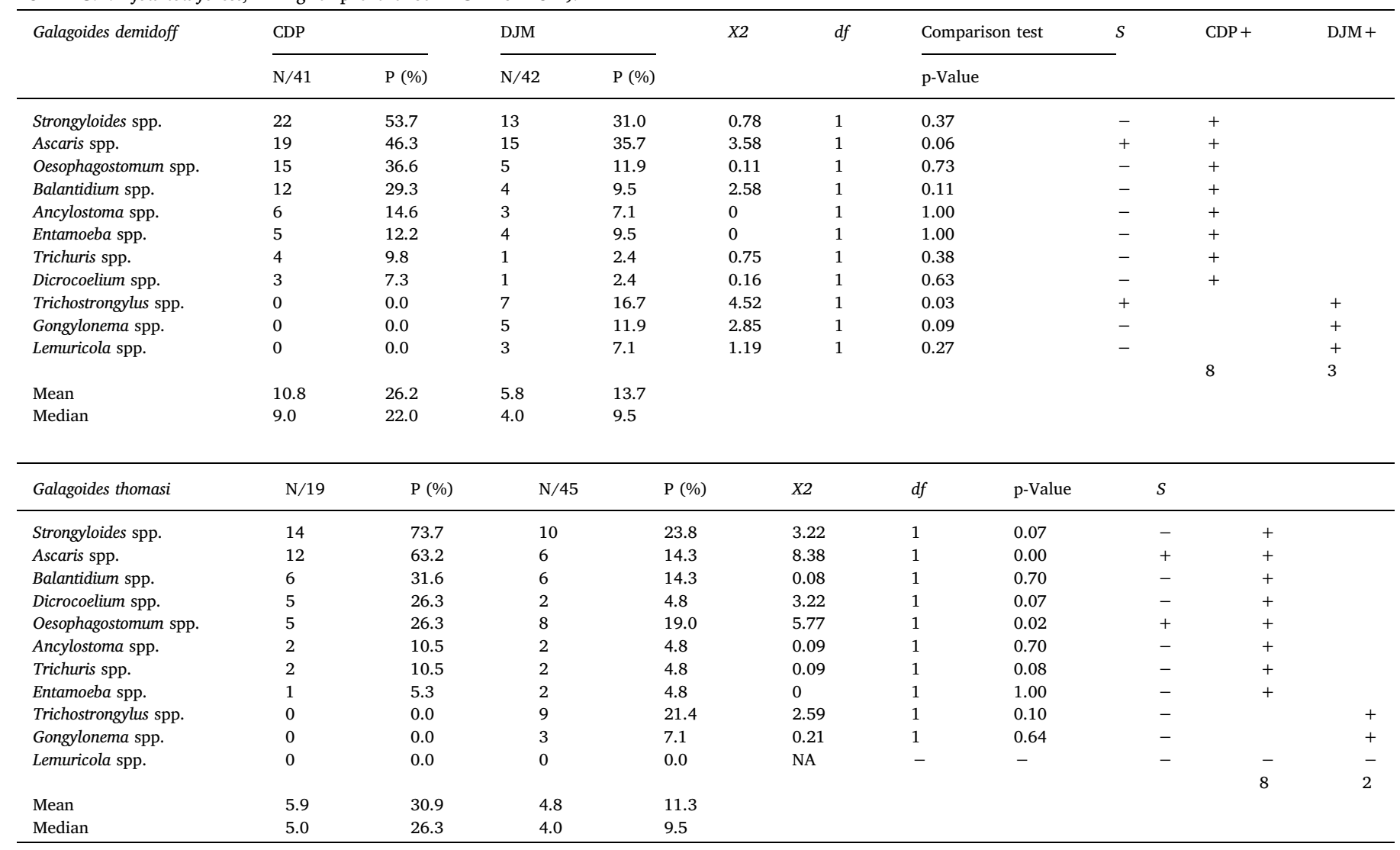

\subsection{Entamoeba spp.}

For both host species the prevalence values are similar and relatively weak $(<10)$ (Table 1$)$; the prevalence is very similar in CDP or DJM and higher in females or young (Tables 2 and 3). Following Golvan (1990) about ten different species of Entamoeba have been identified in Man. A part of them are apparently non pathogenetic. Infection occurs orally, from drinking water, food, etc. E. histolytica is the most frequent, predominantly infecting humans and other primates and distributed worldwide. E. coli is identified as a parasite of chimpanzees and baboons by Howells et al. (2011); the same species was recorded in $\mathbf{E u}$ lemur fulvus E. Geoffroy, 1796 from Madagascar, by Clough et al. (2010). If according to the above, finding Entamoeba spp. in galagos is not surprising more investigations are needed to precise which species is/are present in these particular hosts.

\subsection{Gongylonema spp.}

This parasite is present in both host species with a relatively low prevalence: 4.7 and 6 in $G$. thomasi and G. demidoff respectively (Table 1). It is absent from CDP and more frequent in females or young (Table 3). Members of the genus occur embedded in the mucosa of the anterior region of the gut of birds and mammals (Anderson, 2000). The eggs are evacuated in the outside environment. If ingested by coprophagous insects (cockroaches, dung beetles, etc.) the larvae continue their development in the haemocoel of insects or become encapsulated in their muscles (Quentin et al., 1986). Definitive hosts are contaminated by accidentally swallowing these insects (Golvan, 1990). G. pulchrum is the most frequent and cosmopolitan species. This nematode is usually a parasite of the digestive tract of cattle and swine but Man infestations have been reported in most parts of the world. The high frequency of this parasite in tropical areas, its ubiquity including Man and the fact that insects are intermediary hosts makes plausible its presence in galagos. More investigations are needed to precise which species is/are present in these particular hosts.

\subsection{Lemuricola spp.}

The samples collected in $G$. thomasi are negative all of them. Three individuals of $G$. demidoff only, out of 83 animals examined, were found positive and all of them were captured in DJM. An Oxyurid identified as Enterobius sp. is recorded by Malekani et al. (2014) in a free-living galago: G. demidoff in Congo with a prevalence of 11.1. In a previous work (Hugot et al., 1995) oxyurids were found and described in a closely related host: G. senegalensis E. Geofffroy. But this animal was dead in captivity in the Faculty of Medicine of Paris where it was living in close proximity to a colony of Microcebus murinus (Miller) in a breeding lab. The parasites collected from the galago were morphologically very similar to Lemuricola microcebi, Hugot et al., 1995 considered to be specific for $M$. murinus. Finally because of the low numbers of parasites available for examination, it was decided impossible to choose between: either a transfer from the microcebes to the galago or the possibility that the two samples actually belong to two different species. Until more material or information could be obtained, it was proposed to refer to the parasites of the galago as Lemuricola sp. The results exposed above are giving some consistence to the existence of one or several particular and new parasite species in the galagos. 
Table 3

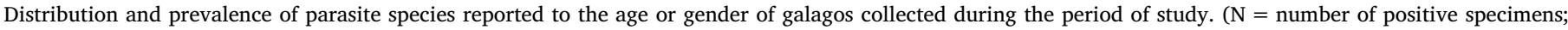
$\mathrm{P}=$ prevalence; $\mathrm{S}=+$, test significant; + higher prevalence in males $(\mathrm{M})$, females $(\mathrm{F})$, adults (A) or young (Y).

\begin{tabular}{|c|c|c|c|c|c|c|c|c|c|c|}
\hline \multirow[t]{2}{*}{ Distribution by gender } & \multicolumn{2}{|l|}{ Male } & \multicolumn{2}{|c|}{ Females } & \multirow[t]{2}{*}{$X 2$} & \multirow[t]{2}{*}{$d f$} & \multirow{2}{*}{$\begin{array}{l}\text { Comparison test } \\
\text { p-Value }\end{array}$} & \multirow[t]{2}{*}{$S$} & \multirow[t]{2}{*}{$\mathrm{M}+$} & \multirow[t]{2}{*}{$\mathrm{F}+$} \\
\hline & $\mathrm{N} / 79$ & $\mathrm{P}(\%)$ & $\mathrm{N} / 68$ & $\mathrm{P}(\%)$ & & & & & & \\
\hline Strongyloides spp. & 38 & 48.1 & 20 & 29.4 & 0.78 & 1 & 0.37 & - & + & \\
\hline Ascaris spp. & 32 & 40.5 & 20 & 29.4 & 3.58 & 1 & 0.06 & - & + & \\
\hline Balantidium spp. & 16 & 20.3 & 10 & 14.7 & 2.58 & 1 & 0.11 & - & + & \\
\hline Dicrocoelium spp. & 8 & 10.1 & 4 & 5.9 & 0.16 & 1 & 0.63 & - & + & \\
\hline Oesophagostomum spp. & 5 & 6.3 & 2 & 2.9 & 0.11 & 1 & 0.73 & - & + & \\
\hline Trichuris spp. & 5 & 6.3 & 4 & 5.9 & 0.75 & 1 & 0.38 & - & + & \\
\hline Lemuricola spp. & 2 & 2.5 & 1 & 1.5 & 1.19 & 1 & 0.27 & - & + & \\
\hline Trichostrongylus spp. & 5 & 6.3 & 11 & 16.2 & 4.52 & 1 & 0.03 & - & & + \\
\hline Ancylostoma spp. & 4 & 5.1 & 9 & 13.2 & 0.00 & 1 & 1.00 & - & & + \\
\hline Entamoeba spp. & 3 & 3.8 & 9 & 13.2 & 0.00 & 1 & 1.00 & + & & + \\
\hline \multirow[t]{2}{*}{ Gongylonema spp. } & 3 & 3.8 & 5 & 7.4 & 2.85 & 1 & 0.09 & - & & + \\
\hline & & & & & & & & & 7 & 4 \\
\hline Mean & 11.0 & 14.9 & 9.0 & 13.2 & & & & & & \\
\hline Median & 5.0 & 6.3 & 7.0 & 10.3 & & & & & & \\
\hline \multirow[t]{2}{*}{ Distribution by age } & \multicolumn{2}{|l|}{ Adults } & \multicolumn{2}{|l|}{ Young } & $X 2$ & $d f$ & Comparison test & $S$ & $\mathrm{~A}+$ & $\mathrm{Y}+$ \\
\hline & $\mathrm{N} / 97$ & $\mathrm{P}(\%)$ & $\mathrm{N} / 50$ & $\mathrm{P}(\%)$ & & & p-Value & & & \\
\hline Strongyloides spp. & 48 & 49.5 & 10 & 20.0 & 4.87 & 1 & 0.03 & + & + & \\
\hline Ascaris spp. & 34 & 35.1 & 18 & 36.0 & 0.26 & 1 & 0.60 & - & - & - \\
\hline Balantidium spp. & 24 & 24.7 & 4 & 8.0 & 6.08 & 1 & 0.01 & + & + & \\
\hline Trichuris spp. & 6 & 6.2 & 3 & 6.0 & 1.12 & 1 & 0.29 & - & - & - \\
\hline Lemuricola spp. & 3 & 3.1 & 1 & 2.0 & 0 & 1 & 1.00 & - & + & \\
\hline Trichostrongylus spp. & 5 & 5.2 & 11 & 22.0 & 3.04 & 1 & 0.08 & - & & + \\
\hline Ancylostoma spp. & 2 & 2.1 & 11 & 22.0 & 4.90 & 1 & 0.02 & + & & + \\
\hline Entamoeba spp. & 4 & 4.1 & 8 & 16.0 & 3.79 & 1 & 0.05 & + & & + \\
\hline Oesophagostomum spp. & 3 & 3.1 & 8 & 16.0 & 1.07 & 1 & 0.30 & - & & + \\
\hline Dicrocoelium spp. & 6 & 6.2 & 6 & 12.0 & 0 & 1 & 1.00 & - & & + \\
\hline \multirow[t]{2}{*}{ Gongylonema spp. } & 4 & 4.1 & 4 & 8.0 & 0.30 & 1 & 0.58 & - & & + \\
\hline & & & & & & & & & 3 & 6 \\
\hline Mean & 12.6 & 13.0 & 8.3 & 15.3 & & & & & & \\
\hline Median & 5.0 & 5.2 & 9.0 & 18.0 & & & & & & \\
\hline
\end{tabular}

\subsection{Oesophagostomum spp.}

With a prevalence of 39.1 for $G$. thomasi this parasite reach the highest value after Ascaris spp. for this host and one of the highest values observed for a parasite in DJM: 19 (Tables 1 and 2). For both host species the prevalence is higher in CDP than in DJM (Table 2) and in the young than in the adults (Table 3). After Golvan (1990): several Oesophagostomum spp. are present in African Primates like macaques, baboons, guenons and gorillas; all of them may contaminate Man who is considered a substitution or abnormal host; the oesophagostomiasis are more common in forest areas. Oesophagostomiasis has no vector, percutaneous infection has never been reported and it is believed that contamination occurs by oral-faecal ingestion of L3 larvae, both for Man or animals. Whether or not parasite transmission is specifically waterborne, foodborne, or both is not elucidated (Ziem, 2006). Future investigations will have to determinate if the parasite(s) observed in this study result of contamination by monkey or ape parasite(s) or are host specific for the galagos.

\subsection{Strongyloides spp.}

The prevalence of this parasite is more than five times higher in $G$. demidoff (62.7) than in G. thomasi (10.9) (Table 1) and for both hosts species the prevalence is higher in CDP than in DJM (Table 2). The prevalence is higher in males than in female, and in adults than in young (Table 3). Non-human primates are known to be the major hosts of Strongyloides spp. (Egido et al., 2001; Kouassi et al., 2015) and particularly for Strongyloides fulleborni Linstow, 1905, a parasite of the monkeys of Asia and Africa. Malekani et al. (2014) recorded a parasite identified as $S$. stercoralis (Bavay, 1876) in G. demidoff in Congo with a prevalence of 14.81. These nematodes are found both in populations living in forested and urban areas. Some "strains" seem perfectly adapted to Man and can therefore be maintained outside the presence of monkeys. It should be noted that in these cases of human infestation, eggs and not larvae are found in stools. Future investigations will have to determinate if the parasite(s) observed in this study result of contamination by monkey or ape parasite(s) or are host specific for the galagos.

\subsection{Trichostrongylus spp.}

The prevalence for this parasite is much higher in $G$. thomasi $(23.4 \mathrm{vs}$ 1.2) and it is observed in DJM, only. The prevalence is about three times higher in the females than in the males (16.2 vs 6.3), and in the young than the adults (22 vs 5.2) (Table 3). According Golvan (1990), Trichostrongylus spp. are cosmopolitan and above all parasites of Ruminants, Lagomorphs and Rodents sometimes also from Equidae. In Africa these parasitosis are known in Man and monkeys: the eggs are eliminated in the stools and the faeco-oral contamination of Primates considered resulting from absorption of plants soiled by droppings of domestic animals (Munene et al., 1998). This modality of infection looks unlikely or almost difficult for galagos, which are strictly arboreal. However Trichostrongylus spp. were recorded both in G. demidoff and G. gabonensis in Congo by Malekani et al. (2014) with a prevalence of 50 for each host species. The fact that the prevalence is greater on the site where interactions with Man are less frequent (DJM) doesn't make very plausible a contamination by human parasites. A precise identification of the parasite(s) identified as Trichostrongylus spp. is necessary before we can interpret this observation. 


\subsection{Trichuris spp.}

The prevalence for this parasite is one of the lowest in both host species: 3.6 vs 9.4 (Table 1). Its prevalence is higher in CDP and quite identical in males, females, and adults or young $(\approx 6)$ (Tables 2 and 3 ). The eggs of this parasite localized in the small intestine are evacuated in the external environment with the stool. The eggs are extremely resistant to atmospheric and chemical agents and must stay in the ground during 6 to 12 months before to be infective. Man may be infested with fruits or vegetables growing on ground and raw (Golvan, 1990). About 60-70 species of whipworms have been recorded from mammals (primates, artiodactyls, rodents, lagomorphs, shrew, felids and foxes) and they are cosmopolitan (Anderson, 2000). T. trichiura is a parasite of humans and other primates and is regarded as the second most common parasitic infection in humans in the tropics. Ooi et al. (1993), described specimens from Macaca fuscata and Papio papio as T. trichiura. Future investigations will have to determinate if the parasite(s) observed in this study result of contamination by Man, monkey or ape parasite(s) or are host specific for the galagos.

\section{Discussion}

Recently several works were published regarding the parasitic fauna of African NHPs (Landsoud-Soukate et al., 1995; Clough et al., 2010; Nath et al., 2012; Kalousová et al., 2014) but only one of them concerned the galagos: Malekani et al. (2014). Unfortunately, if this work is providing a first sight on the diversity of the gastro-intestinal parasite fauna in two galago species, the observations are founded on a relatively low number of specimens $(N=30)$ captured in not least than seven different stations of captures. Logically considering this, the positive results are not identified following their localization and no mention of the gender or age of the animals examined is given. This makes difficult a comparison with our own results. Two Cestoda and one Digena recorded in this work are absent of our observations. However, several parasite taxa identified in the present work are also present in Malekani et al. (2014): Ascaris spp., Lemuricola spp., Ancylostoma spp., Trichostrongylus spp. and Strongyloides spp. Because of the characteristics of the cycle of the first two taxa (see discussion above), it seems likely that the parasites observed here may belong to species specific to their hosts and still undescribed.

\subsection{Diversity and prevalence of gastrointestinal parasites by host species (Table 1)}

Data analyses revealed the presence of nine helminth parasites and two protozoa parasites. With the exception of Lemuricola spp., present in G. demidoff only, the same parasite taxa are recorded in both host species. For both host species the arithmetic means of the prevalence values are very close: 14.7 for $G$. demidoff $v s 15.5$ for $G$. thomasi. However, the prevalence values observed for each parasite vary markedly. Two parasites only exhibits a high prevalence whatever which host is considered: Ascaris spp. (31.3 vs 40.6) and Balantidium spp. (19.3 vs 15.6). The differences in prevalence are particularly marked and statistically significant for Strongyloides spp. (62.7 vs 10.9) and Oesophagostomum spp. (9.6 vs 39.1).

\subsection{Difference in prevalence according to collection sites and host species (Table 2)}

Three parasites taxa are never represented in CDP site, whatever which host species is considered: Gongylonema spp., Lemuricola spp. and Trichostrongylus spp. For the other eight parasite taxa the prevalence is systematically higher in CDP than in DJM site, whatever which host species is considered: for $G$. demidoff the mean prevalence is $18.3 \mathrm{vs}$ 11.9 and 20.4 vs 8.6 for $G$. thomasi. Proportionally, for the same parasite, the prevalence in CDP is 1,5 to 4 times its value in DJM for both host species. Finally, if the parasite diversity appears to be higher in DJM, several parasites reach their highest prevalence value in CDP; for G. demidoff: Strongyloides spp. (53.7), Ascaris spp. (46.3); for G. thomasi: Strongyloides spp. (73.7), Ascaris spp. (63.2). CDP forest is more fragmented and impacted by human activities than DJM. Previous studies have shown that these factors may influence the diversity and prevalence of parasites, particularly because forest fragmentations reduce food availability and increase host densities (Gillespie and Chapman, 2008).

\subsection{Difference in prevalence according to the age or gender of the host species (Table 3)}

In our data set the effectives of males or females are quite equivalent: 79 vs 68; conversely the contrast between the representation of adults or young is high: $97 v s 50$.

\subsubsection{Gender}

For both sexes the highest prevalence values deal with the same parasite taxa: Ascaris spp., Balantidium spp. and Strongyloides spp. The mean prevalence values are higher for the males than the females: 14.7 vs 11.0. However the females have a relatively stronger prevalence than the males for four parasites: Ancylostoma spp. (13.2 vs 5.1), Trichostrongylus spp. (16.2 vs 6.3), Gongylonema spp. (7.4 vs 3.8) and Entamoeba spp. (13.2 vs 3.8). Within the males the contrast between the highest $v s$ the lowest prevalence values is higher (median $=6.3$ ) than within the females (median $=10.3$ ). These differences may be related with the particular behavior of the galagos where matriarchal groups are the stable units, with a family defending a territory during nomadic males are travelling over several female territories every night (Kingdon, 1997).

\subsubsection{Age}

The mean prevalence values are relatively close when the adults are compared to the young: 13.0 vs 15.3; for both class the highest prevalence values deal with the same parasite taxa: Ascaris spp. (35.1 vs 36.0) and Strongyloides spp. (49.5 vs 20.0). The young have a markedly stronger prevalence (two to ten times higher) than the adults for six parasite taxa out of 11: Ancylostoma spp. (22.0 vs 2.0), Dicrocoelium spp. (12.0 vs 6.2), Entamoeba spp. (16.0 vs 4.1), Gongylonema spp. (8.0 vs 1.0), Oesophagostomum spp. (16.0 vs 3.1) and Trichostrongylus spp. (22.0 $v s$ 5.2). However, the differences in prevalence are statistically significant ( $\chi^{2}$ test) only for Ancylostoma spp., Balantidium spp., Entamoeba spp. and Strongyloides spp. Within the adults the contrast between the highest $v s$ the lowest prevalence values is higher (median $=7.2$ ) than within the young (median $=14.0$ ). MacIntosh et al. (2010) and Mbaya and Udendeye (2011) have shown the existence of a link between age and gastrointestinal parasites infestation. The fact that young are more infected could be explained by their higher susceptibility to helminthiasis due to a lack of premunity (acquired immunity through exposure). The highest values observed in adults for some parasites may be related to to the phenomenon of surinfestation (increasing population of a parasite in one host due to successive reinfestations).

\subsection{Conclusion}

Our work reveals very similar parasite spectrum in both host species and it is notable that all the taxa identified here were found previously in other Primate species, including Man. Because the hosts are closely related and living in sympatry a questions arise for each identified parasite taxon: is it specific for the Primates as a whole, for the Galago spp., or is it strictly host specific? To answer to this question it is needed to be able to identify precisely the parasites at the species level.

This point also deals with a hypothetical role of some parasites as zoonotic agents. Because the galagos are strictly arboreal and nocturnal and are not considered to be game animals, the contamination of Man 
by galagos parasite(s) or the contaminations of galagos directly by Man looks unlikely. Obviously this observation is not valid for zoonotic parasites having a ubiquitous host spectrum. However and whatever which host is considered a majority of parasites have a higher prevalence in CDP site. For this reason the influence of a closer cohabitation with Man including a fragmentation of the galagos habitats may be considered.

When compared with females, males generally exhibit higher prevalence values for $7 / 11$ parasite taxa; males also reach the highest prevalence values observed during our study for several parasites. This may be related with the behavioral differences between galago males or females.

The young have a higher prevalence value for $6 / 11$ parasite taxa and an equal prevalence for two of them. This may be interpreted in the context of a higher sensibility to parasitism and diseases probably partially linked with an immature immune system.

Measures to protect the environment and endangered species oblige parasitologists to change their method of study. It is no longer possible to dissect numerous animals in order to collect their internal parasites. The determination of the parasites may possibly be improved through the use of molecular analysis methods. Unfortunately these methods were not usable in the context of the present study. We therefore used available data on geographical distribution, host spectrum and host specificity of the parasitic taxa in an attempt to identify them. For these reasons, this work must be considered preliminary and, in order to try to answer to the questions it asks, additional observations are needed. This includes predominately the identification and if possible the description of the parasite taxa.

\section{Acknowledgements}

This research did not receive any specific grant from funding agencies in the public, commercial, or not-for-profit sectors.

\section{References}

Alonso, A., Lee, M., Campbell, P., Pauwels, O., Dallmeier, F., 2006. Gamba, Gabon: biodiversity of an equatorial African rainforest. Bull. Biol. Soc. Wash. 12, 1-436.

Anderson, R.C., 2000. Nematode Parasites of Vertebrates. Their Development and Transmission, 2nd ed. CAB. International, London, UK, pp. 578.

Ashford, R., Crewe, W., 2003. Parasites of Homo sapiens: An Annotated Checklist of the Protozoa, Helminths and Arthropods for Which We Are Home. CRC Press, pp. 153.

Bavay, A., 1876. Sur tanguillule stercorale. C. R. Acad. Sci. (Paris) 83, 694-696.

Chitwood, B., Chitwood, M., Christenson, R., Jacobs, L., Wallace, F., 1950. An Introduction to Nematology: Section 1: Anatomy. Printed in the United States of America: Monumental Printing Company Baltimore. pp. 217.

Clough, D., Heistermann, M., Kappeler, P.M., 2010. Host intrinsic determinants and potential consequences of parasite infection in free-ranging red-fronted lemurs (Eulemur fulvus rufus). Am. J. Phys. Anthropol. 142 (3), 441-452.

Combes, C., 1995. Interactions Durables. Ecologie et évolution du parasitisme. Masson, pp. 524.

Daszak, P., Cunningham, A.A., Hyatt, A.D., 2000. Emerging infectious diseases of wildlifethreats to biodiversity and human health. Science 287 (5452), 443.

Duplantier, J.M., 1989. Les rongeurs myomorphes forestiers du nord-est du Gabon: structure du peuplement, démographie, domaines vitaux. Rev. Ecol. 4, 329-346.

Egido, J.M., De Diego, J.A., Penin, P., 2001. The prevalence of enteropathy due to strongyloidiasis in Puerto Maldonado (Peruvian Amazon). Braz. J. Infect. Dis. 5 (3), 119-123.

Gillespie, T.R., 2006. Noninvasive assessment of gastrointestinal parasite infections in free-ranging primates. Int. J. Primatol. 27 (4), 1129.
Gillespie, T.R., Chapman, C.A., 2008. Forest fragmentation, the decline of an endangered primate, and changes in host-parasite interactions relative to an unfragmented forest. Am. J. Primatol. 70 (3), 222-230.

Golvan, Y., 1990. Atlas de Parasitologie (Schémas explicatifs d'épidémiologie). Éditions Le Léopard d'Or, Paris, pp. 323.

Graber, M., Gevrey, J.P., 1981. Parasites internes des primates de la République Démocratique du Congo (d'après la collection Cassard-Chambrom 1956-1960). Rôle pathogène-diagnostic prophylaxie. Rev. Elev. Med. Vet. Pays Trop. 34 (1), 27-41.

Hochachka, W.M., Dhondt, A.A., 2000. Density-dependent decline of host abundance resulting from a new infectious disease. Proc. Natl. Acad. Sci. U. S. A. 97 (10), 5303-5306.

Howells, M.E., Pruetz, J., Gillespie, T.R., 2011. Patterns of gastro-intestinal parasites and commensals as an index of population and ecosystem health: the case of sympatric western chimpanzees (Pan troglodytes verus) and Guinea baboons (Papio hamadryas papio) at Fongoli, Senegal. Am. J. Primatol. 73 (2), 173-179.

Hudson, P.J., Rizzoli, A., Grenfell, B.T., Heesterbeek, H., Dobson, A.P., 2002. The Ecology of Wildlife Diseases. Oxford University Press, Oxford, pp. 216.

Hugot, J.P., Morand, S., Gardner, S.L., 1995. Morphology and Morphometrics of three oxyurids parasitic in primates. Description of Lemuricola microcebi n. sp. Int. J. Parasitol. 25 (9), 1065-1075.

Hugot, J.P., Baujard, P., Morand, S., 2001. Biodiversity in helminths and nematodes as a field of study: an overview. Nematology 3 (3), 199-208.

Kalousová, B., Piel, A.K., Pomajbíková, K., Modrý, D., Stewart, F.A., Petrželková, K.J., 2014. Gastrointestinal parasites of savanna chimpanzees (Pan troglodytes schweinfurthii) in Ugalla, Tanzania. Int. J. Primatol. 35 (2), 463-475.

Kingdon, J., 1997. Kingdon Field Guide to African Mammals. Princeton University Press, pp. 496.

Kouassi, R.Y.W., McGraw, S.W., Yao, P.K., Abou-Bacar, A., Brunet, J., Pesson, B., Bonfoh, B., N'goran, E.K., Candolfi, E., 2015. Diversity and prevalence of gastrointestinal parasites in seven non-human primates of the Taï National Park, Côte d'Ivoire. Parasite 22 (1), 1-12.

Landsoud-Soukate, J., Tutin, C.E.G., Fernandez, M., 1995. Intestinal parasites of sympatric gorillas and chimpanzees in the Lopé reserve. Gabon. Ann. Trop. Med. Parasitol. 89 (1), 73-79.

Lyles, A.M., Dobson, A.P., 1993. Infectious disease and intensive management: population dynamics, threatened hosts, and their parasites. J. Zoo. Wildlife Med. 24 (3), 315-326.

MacIntosh, A.J., Hernandez, A.D., Huffman, M.A., 2010. Host age, sex, and reproductive seasonality affect nematode parasitism in wild Japanese macaques. Primates 51 (4), 353-364.

Malcolm, J.R., 1991. Comparative abundances of Neotropical small mammals by trap height. J. Mammal. 72 (1), 188-192.

Malekani, J.M., Ngobula, K.N., Tshabu, G.T., Liyandja, T.L.D., Pambu, A.L., Kalemba, L.N., Mwanza, F.B., Malekani, D.V., Ashande, M.C., Bongo, G.N., 2014. Epidemiological monitoring of gastrointestinal helminthes of two wild Galagos: Galagoides demidovii and Sciurocheirus gabonensis (primates, Galagidae) originated from Democratic Republic of the Congo. J. Adv. Med. Life Sci. 2 (2), 1-4.

Mbaya, A.W., Udendeye, U.J., 2011. Gastrointestinal parasites of captive and freeroaming primates at the Afi Mountain Primate Conservation area in Calabar, Nigeria and their zoonotic implications. Pak. J. Biol. Sci. 14 (13), 709-714.

Munene, E., Otsyula, M., Mbaabu, D.A., Mutahi, W.T., Muriuki, S.M., Muchemi, G.M. 1998. Helminth and protozoan gastrointestinal tract parasites in captive and wildtrapped African non-human primates. Vet. Parasitol. 78 (3), 195-201.

Nath, B.G., Islam, S., Chakraborty, A., 2012. Prevalence of parasitic infection in captive non human primates of Assam state zoo, India. Vet. World 5 (10), 614-616.

Ooi, H.K., Tenora, F., Itoh, K., Kamiya, M., 1993. Comparative study of Trichuris trichiura from non-human primates and from man and their difference with T. suis. J. Vet. Med. Sci. 55, 363-366.

Pauwels, O.S., Burger, M., Branch, W.R., Tobi, E., Yoga, J.A., Mikolo, E.N., 2006. Reptiles du Complexe d'Aires Protégées de Gamba, sud-ouest du Gabon. Bull. Biol. Soc. Wash. 12, 91-100.

Quentin, C., Seureau, C., Sapin, J.M., 1986. Gongylonema congolense Fain, 1955, (Nematoda, Spirurida) synonymie et biologie larvaire, réactions cellulaires de l'insecte hôte intermediare. Z. Parasitenk. 72, 227-239.

Wilson, D.E., Reeder, D.M., 2005. Mammal Species of the World: A Taxonomic and Geographic Reference, Baltimore, É.-U. Johns Hopkins University Press, pp. 2142.

Wolfe, N.D., Dunavan, C.P., Diamond, J., 2007. Origins of major human infectious diseases. Nature 447 (7142), 279-283.

Ziem, J.B., 2006. Controlling Human Oesophagostomiasis in Northern Ghana. Thèse de Doctorat de l'Université de Leiden, Pays Bas. 